\title{
La Diputación de Vizcaya en el siglo XVIII, una institución emergente $(1750-1800)^{*}$
}

\section{Fernando Martínez Rueda \\ $\mathrm{UPV} / \mathrm{EHU}$}

RESUMEN: El presente artículo analiza el proceso de fortalecimiento institucional de la Diputación General del Señorio de Vizcaya desarrollado durante la segunda mitad del siglo XVIII. Desde el punto de vista metodológico, utilizamos una doble perspectiva. Por un lado, observamos las consecuencias que la relación institucional entre la Monarquía y el Señorio de Vizcaya tuvo para la Diputación en la época del denominado Absolutismo Ilustrado. Por otro lado, analizamos la dinámica institucional interna, es decir, la relación de la Diputación con otras instituciones del Señorio como el Corregidor y las corporaciones locales vizcaínas, en el marco de un entramado institucional foral plural y complejo. Todo ello nos permite concluir que durante las últimas décadas del siglo XVIII la Diputación ensanchó notablemente su ámbito de poder, adquirió una posición preeminente sobre otros poderes y jurisdicciones del orden foral y se convirtió para la Monarquía en instrumento necesario para aplicar en Vizcaya sus órdenes y algunas de sus reformas.

\section{PALABRAS ClAVE: Diputación; Vizcaya; instituciones forales; Monar- quía; Absolutismo Ilustrado.}

The Diputacion (Council) of Biscay in the XVIII Century, a Rising Institution (17501800)

ABSTRACT: This paper analyses the institutional strengthening process of the Diputación (Council) of Biscay developed during the second half of the XVIII

* Abreviaturas utilizadas: Archivo Histórico Nacional (AHN); Archivo Foral de Bizkaia (AFB); Archivo de la Real Chancillería de Valladolid, Sala de Vizcaya (ARChV, SV); Archivo Municipal de Bilbao (AMB); Archivo Municipal de Basauri (AMBa). Este trabajo ha sido realizado en el seno del Grupo de Investigación consolidado IT653-13 del Departamento de Historia Contemporánea de la UPV/EHU. 
Century. From the methodological point of view, a dual perspective is used. On one hand, attention is focused on the consequences that the relationship between the Crown and the Señorío of Biscay had for the Diputación (Council) during the period known as the Enlightened Absolutism. On the other hand, the internal institutional development is analysed, i.e., the relationship between the Diputacion (Council of Biscay) with other institutions of the Señorío - as the Corregidor and the local governments - coexisting in the complex and plural foral framework. It can be concluded that the during the last decades of the XVIII Century the Diputación (Council of Biscay) broadened its scope of power, achieved a pre-eminent position over other powers and jurisdictions of the foral system and became a necessary tool for the Monarchy to apply its orders and some of its reforms in Biscay.

KEY WORDS: Diputación (Council); Biscay; foral institutions; Monarchy; Enlightened Absolutism.

\section{INTRODUCCIÓN}

Uno de los rasgos característicos más singulares de la foralidad vasca ha sido su extraordinaria longevidad. Conjunto de usos y costumbres de origen medieval, los fueros de los territorios vascos no sólo perduraron durante toda la Edad Moderna, sino que también sobrevivieron a la ruptura liberal mediante la ley de 25 de octubre de 1839 que los confirmó «sin perjuicio de la unidad constitucional de la Monarquía». Incluso tras la abolición de las instituciones forales decretada por Cánovas en 18771, las Diputaciones provinciales vascas gozaron de amplia autonomía fiscal y administrativa, justificada por el pasado foral de las antiguas provincias exentas. En la Transición la cuestión foral fue de nuevo planteada por el nacionalismo vasco en el debate constitucional $^{2}$. Como es sabido, la Constitución de 1978 recogió finalmente una disposición adicional que amparaba «los derechos históricos de los territorios forales». Esa disposición fue utilizada en el estatuto de autonomía de 1979 para dar una configuración institucional foral a la Euskadi autónoma, basada en la existencia de Juntas Generales y Diputación foral en cada uno de los territorios históricos que constituyen la Comunidad Autónoma Vasca.

Esa excepcional perduración de la foralidad ha sido posible, obviamente, por su extraordinaria capacidad de transformarse y redefinirse para adaptarse a las diferentes coyunturas históricas y a los diversos sistemas políticos. Si en el ámbito discursivo se ha hablado de la metamorfosis del fuerismo ${ }^{3}$ para alu-

1 CASTELLS, 52 (Madrid, 2003): 117-149.

2 ARRIETA, 19 (Madrid, 2012): 39-52.

3 FERNÁNDEZ SEBASTIÁN, 4 (Bilbao, 1990): 61-87. MINA, 4 (Bilbao, 1990): 89-106. 
dir al continuo proceso de adaptación del corpus ideológico legitimador de la foralidad, también en la esfera institucional podemos hablar de una auténtica mutación del sistema foral en el devenir histórico. La evolución de la Diputación General del Señorío de Vizcaya es buena muestra de esa profunda transformación institucional. Hasta finales del siglo XVII fue una institución inexistente primero y secundaria después ${ }^{4}$. Sin embargo, para el XIX la Diputación se había convertido en el núcleo institucional del régimen foral, cuando éste fue definido sustancialmente como un singular sistema de gobierno y administración de las provincias vascas, controlado por sus propias instituciones forales y sobre todo por sus respectivas Diputaciones 5 . Ese proceso decimonónico de redefinición de la foralidad fue posible, entre otros factores, por el previo fortalecimiento institucional de la Diputación desarrollado durante la segunda mitad del siglo XVIII.

En las siguientes líneas estudiamos ese proceso de robustecimiento institucional de la Diputación ocurrido entre 1750 y 1800. Para ello, distinguiremos dos niveles de análisis. De puertas afuera, observaremos las consecuencias que la dinámica institucional entre la Monarquía y el Señorío de Vizcaya tuvo para la Diputación de Vizcaya. Trataremos de ponderar hasta qué punto las reformas del denominado Despotismo Ilustrado debilitaron o consolidaron la institución. De puertas adentro, y dado que el entramado foral era un orden plural y complejo en el que concurrían diversos poderes y jurisdicciones, analizaremos la forma en que la Diputación fue adquiriendo una posición preeminente sobre otras instituciones del Señorío como el Corregidor o las corporaciones locales vizcaínas. Todo ello nos permitirá conocer las atribuciones que llegó a alcanzar la Diputación General a finales del Antiguo Régimen, cuestión de importancia para explicar la singular evolución de la foralidad durante los tiempos contemporáneos y su excepcional duración.

4 En 1566 nació el denominado Regimiento particular, que desde mediados del siglo XVII empezó a recibir el nombre de Diputación. Pero en esa época desempeñaba un papel secundario en el entramado foral. Sólo a partir de 1695 empezó a actuar como organismo autónomo, con atribuciones propias, no dependiente de otras instituciones forales. Sobre los antecedentes y etapa inicial de la Diputación, MONREAL, 1974: 410-426. AREITIO, 1943: 43-71.

5 Desde diferentes perspectivas de análisis (institucional, hacendística, jurídica o ideológica) varios autores han observado ese proceso de redefinición y transformación de la foralidad en el siglo XIX: PÉREZ NÚÑEZ, 1996; AGIRREAZKUENAGA, 1987 y 2011; PORTILLO, 1987 y 2006; CLAVERO, 1985; RUBIO, 1996.

6 CLAVERO, 58 (Madrid, 1988): 543-559. LÓPEZ ATXURRA, 2004, vol. 3: 83-105. PORTILLO, 1991: 370-402. 


\section{LA MONARQUía, LOS FUEROS Y LA DIPUTACIÓN DE VIZCAYA}

El establecimiento de la nueva dinastía borbónica a inicios del siglo XVIII conllevó importantes cambios en la forma de gobernar el reino. Aunque de forma singular, algunas de esas transformaciones también afectaron a los territorios vascos. Como consecuencia de la aplicación de los decretos de Nueva Planta, las provincias vascas y el reino de Navarra se convirtieron en los únicos espacios de la Monarquía dotados de un derecho territorial y de unas sólidas instituciones propias. Por otro lado, la nueva dinastía trató de reforzar el poder del soberano mediante la utilización creciente de vías ejecutivas de gobierno, en detrimento de las tradicionales de carácter judicial, con el objetivo de acometer reformas que pretendían fortalecer a la Monarquía y aumentar sus recursos. Se fue así configurando una Monarquía administrativa que trataba de impulsar una acción de gobierno más directa y eficaz desde la Corte ${ }^{7}$ y que colisionó con la defensa foral realizada por las instituciones de las provincias exentas. En ese contexto se desarrolló la dialéctica entre reforma borbónica y privilegio foral, característica de la época del denominado Despotismo Ilustrado ${ }^{8}$.

Para defender su concepción de la foralidad en el nuevo contexto político de la Monarquía borbónica, la Diputación impulsó la formulación de la interpretación oficial del fuero. El encargado de su elaboración fue Pedro de Fontecha y Salazar, Consultor perpetuo del Señorío. Su obra, Escudo de la más constante fe y lealtad, es el texto que mejor expresa el discurso foral defendido por las autoridades provinciales del siglo XVIII ${ }^{9}$. Sostenía que el derecho foral estaba por encima de la voluntad del monarca, que en ningún caso podía menoscabarlo. Según este relato, el Señorío era una comunidad políticamente constituida, dotada de su propia constitución territorial, con carácter previo a la elección del Señor. En un momento posterior esta comunidad habría elegido Señor a Jaun Zuria, con la condición de guardar sus leyes fundamentales. Esa misma condición de preservar el patrimonio jurídico de la comunidad se habría mantenido cuando el Señorío se unió a la Corona de Castilla. Según Fontecha, para garantizar ese compromiso de respetar el derecho provincial existían figuras jurídicas como el uso o pase foral y los monarcas se comprometían mediante la ceremonia del juramento a respetar los fueros. El Escudo expresaba, en suma, la visión pactista del fuero de las instituciones y élites provinciales. Sus argumentos se repetían una y otra vez en las represen-

7 FERNÁNDEZ ALBALADEJO, 1989, vol. 1: 1-89.

8 PORTILLO, 1991: 549.

9 El Consultor proporcionaba a la Diputación dictámenes y argumentos jurídicos para la defensa del fuero, convirtiéndose de esta manera en su intérprete oficial. Sobre Fontecha y el Escudo..., vid. MAÑARICUA, 1973: 207-225 y ARRIETA, 1 (San Sebastián, 2002): 131-148. 
taciones que los Diputados Generales dirigían a la Corte cuando la Monarquía trataba de aplicar alguna medida que era considerada contraria a los fueros. Este discurso fue operativo durante la segunda mitad del siglo XVIII y sólo a inicios del siglo XIX la Monarquía lo cuestionó abiertamente, a través de obras que consideraban los fueros como graciosas concesiones del monarca que, por tanto, podían ser alteradas por éste de forma unilateral ${ }^{10}$.

Ese discurso foral, basado en la intangibilidad del derecho territorial, se oponía a algunas medidas y mecanismos de gobierno del denominado despotismo ilustrado. Como el fuero señalaba cuáles eran las autoridades jurisdiccionales que el Rey podía nombrar en el Señorío, las elites provinciales rechazaban que la Corona introdujera nuevas autoridades y procedimientos ejecutivos de gobierno. También sostenían que algunas reformas que la Monarquía quería aplicar en materia de aduanas o de hacienda lesionaban las exenciones vizcaínas reconocidas por el fuero. En torno a esas cuestiones se fue desenvolviendo la dialéctica entre reforma y privilegio ${ }^{11}$, cuyo balance fue complejo y dispar en diferentes materias.

La historiografía tradicional ha interpretado esa dialéctica como un permanente enfrentamiento entre centro y periferia, achacando a la Monarquía una política de acoso antiforal que perseguía acabar con «las libertades vizcaínas». Sin embargo, un examen más detallado de la cuestión muestra que la Corona y el poder provincial tendían a buscar soluciones de compromiso. A través de agentes, diputados en Corte o protectores influyentes se establecía una suerte de negociación, tratando de conciliar la aplicación de las reformas monárquicas y el orden foral, aunque no faltaran desencuentros y tensiones debidos a la diferente interpretación sobre el alcance y significado de la foralidad ${ }^{12}$.

En algunas materias, como el control del contrabando y la cuestión aduanera, la Corona mostró una actitud de cierta firmeza, a pesar de la oposición de las autoridades forales a sus medidas. La ubicación de las aduanas en la frontera con Castilla permitía a las provincias exentas importar mercancías sin recargo arancelario, de acuerdo a la libertad de comercio foral ${ }^{13}$, lo que generaba contrabando de materias como cacao, tabaco y moneda. En la Corte se desconfiaba de las autoridades forales para reprimir esos tráficos ilícitos ${ }^{14}$. Por eso, la Monarquía decidió establecer una nueva autoridad jurisdiccional para evitar el contrabando. En 1740 nombró a Manuel Orcasitas Veedor del

10 FERNÁNDEZ PARDO, 1990: 41-78. VIEJO y PORTILLO, 1994: 25-76.

11 PORTILLO, 1991: 549-562.

12 MARTÍNEZ RUEDA, 14 (2013): 129-147. Disponible en: http://www.historiaconstitucional.com [consultado el 20 de diciembre de 2013].

13 Ley X del título primero del Fuero: «Que habían de Fuero, uso y costumbre y libertad, que los dichos vizcaínos Hijosdalgo fuesen y sean libres y exentos para comprar y vender y recibir en sus casas todas cualesquier mercaderías...»

14 ANGULO, 1995: 205-231. 
Contrabando de Mar. El Señorío expuso al Rey que la nueva figura jurisdiccional era ajena al ordenamiento foral, por lo que eran las justicias ordinarias y el Corregidor, que según decían era a la vez «Juez Veedor del comercio y contrabando», quienes debían encargarse de la materia ${ }^{15}$. A pesar de ello, en 1762 la Monarquía insistió en establecer un Subdelegado y Juez de Contrabando del Señorío, nombrando para el cargo a Manuel de Mollinedo. La negativa de las autoridades forales a darle posesión, con el consabido argumento de que era una figura jurisdiccional extraña al ordenamiento foral, fue enérgicamente contestada por el Secretario del Despacho de Hacienda, Marqués de Esquilache, quien conminó a los Diputados a que obedecieran las Reales Órdenes que, según les decía, «se obedecen y no se consultan» ${ }^{16}$. Les proponía que, en caso de considerar el nombramiento contrafuero, recurriesen a los tribunales, pero siempre después de haber dado posesión de su cargo a Mollinedo. A pesar de la introducción de la jurisdicción de contrabando, la singular situación aduanera de las provincias exentas continuó siendo una oportunidad para tráficos ilícitos que perjudicaban a la real hacienda, según escribía en 1770 el ministro Miguel de Musquis a la propia Diputación ${ }^{17}$. Finalmente, la Corona adoptó diversas medidas cuyo fin último era presionar a las autoridades forales para que aceptaran el traslado de las aduanas a la costa. Se trataba de hacer ver a las élites vascas que el mantenimiento de las aduanas en el interior les causaba más perjuicios que ventajas. Ese era el objetivo del Reglamento de libre comercio de 1778, que condicionaba al traslado aduanero la habilitación de los puertos vascos para el comercio ultramarino, y el del establecimiento en 1779 de un derecho de extranjería sobre manufacturas vascas introducidas en el mercado peninsular ${ }^{18}$. Sin embargo, las elites provinciales prefirieron mantener sin cambio alguno el ordenamiento fora ${ }^{19}$, aunque ello perjudicara gravemente los intereses de los comerciantes locales.

En otras materias, por el contrario, la Monarquía adoptó posturas más proclives al acuerdo con las elites provinciales, tratando de adaptar sus medidas al ordenamiento foral y permitiendo que fueran las propias autoridades del Señorío quienes ejecutaran sus reformas. Así ocurrió con el Real Decreto e Instrucción de 1760 que creaba la Contaduría General de Propios y Arbitrios con el fin de controlar las haciendas locales desde el Consejo de Castilla, con el apoyo de los Intendentes de Ejército y Provincia. Las autoridades forales consideraban que la medida era contraria a los fueros. A los intentos monár-

15 FONTECHA, s/a: 181-198. PORTILLO, 1991: 595-597.

16 AFB, AJ 3182/16, 1762 y 3/31, 1762-1763.

17 Libro copiador de oficios y representaciones emitidos por el Señorio, 1766-1794, AFB, AJ 1487/3, 1770.

18 ASTIGARRAGA, 2 (San Sebastián, 2003): 121-154.

19 Acta de la Conferencia de Mondragón de los representantes de las provincias vascas, 16 de octubre de1780, reproducida en AGIRREAZKUENAGA, 1995: 109-119. 
quicos de centralizar las haciendas locales oponían «la nativa libertad, costumbre y posesión inmemorial en que se hallan sus pueblos de la privativa dirección, gobierno y distribución económica de sus rentas y arbitrios conforme a su constitución ${ }^{20}$. Ante la oposición de la Diputación, la Monarquía modificó los aspectos de la reforma contrarios al fuero, pero manteniendo su espíritu. Por un lado, decidió eximir al Señorío de la contribución del $2 \%$ del producto de propios y arbitrios, destinado a cubrir los gastos de la Contaduría. Por otro, ordenó que en lugar del intendente, fueran el propio Corregidor y su Teniente quienes controlaran y remitieran anualmente a la Contaduría las cuentas de los pueblos. A pesar de ello, la Diputación envió nuevos memoriales y peticiones a la Corona con lo que consiguió dilatar y dificultar la aplicación de la Instrucción. Aunque desde los años 60 del siglo XVIII el Corregidor y sus auxiliares incrementaron su labor de inspección sobre las haciendas locales, lo cierto es que la reforma hacendística de 1760 no llegó a aplicarse plenamente en Vizcaya, tal como reconocía el Teniente de Corregidor en 1797: «la Real Orden del Consejo (...) relativa a la anual dación de cuentas y su remesa a la superioridad no ha logrado su ejecución en este Señorío» ${ }^{21}$.

La Diputación General mostró mejor disposición para poner en práctica las reformas monárquicas cuando era ella misma la encargada de ejecutarlas. Así ocurrió, por ejemplo, en el ámbito de la política forestal. En esta materia la Monarquía aprobó en 1748 la Ordenanza para la conservación y aumento de los montes de la marina que ponía el cuidado y conservación de los montes bajo la jurisdicción de los Intendentes de Marina de Cádiz, Ferrol y Cartagena. La Diputación rechazó la medida ya que, una vez más, se negaba a aceptar autoridades extrañas al ordenamiento foral. Finalmente, la Monarquía aceptó modificar la Ordenanza para aplicarla en Vizcaya de acuerdo al fuero, encomendando a la Diputación la jurisdicción gubernativa y al Corregidor la contenciosa en esta materia, en lugar de a los Intendentes de Marina. Utilizando las atribuciones reconocidas por la Corona, las Juntas Generales de 1752 aprobaron un Reglamento de montes que establecía las normas que los pueblos debían cumplir en la materia y subrayaba que correspondía a la Diputación «la jurisdicción gubernativa, política y económica en punto a montes». Por Real Orden de 27 de noviembre de 1784 la Corona sancionó el Reglamento de Montes $^{22}$, que fortalecía las capacidades del poder provincial.

Algo similar ocurrió con el control del orden público y represión de la criminalidad. La Real Instrucción de 29 de junio de 1784 encargó a los Capi-

20 AFB, Reales Cédulas y escrituras originales, $n^{\circ} 144$. Sobre la aplicación de las reformas hacendísticas en las provincias vascas, vid. PORTILLO, 1991: 555-576.

21 Auto de Visita de 1797, AMBa, Libro de cuentas, 1748-1804. SAGARMINAGA, 1892, vol. 4: 376-377, 472-474; vol. 5: 55-61, 74-76.

22 SAGARMINAGA,1892, vol. 4: 209-211; vol. 5: 107-108. AFB, AJ 679/18; AJ 1259/8. PORTILLO, 1991: 413-421. 
tanes Generales la persecución de la delincuencia. Para aplicarla se formaron cuerpos policiales bajo el mando de los respectivos Capitanes Generales, de forma que el ejército se convirtió en elemento básico del modelo de seguridad del Despotismo Ilustrado ${ }^{23}$. El Señorío se opuso a la aplicación de la Real Orden, insistiendo en su tradicional rechazo a la introducción de nuevas autoridades. Finalmente, la Corona aceptó que fuera la Diputación quien se encargara en Vizcaya «de limpiar su distrito de ladrones, contrabandistas y malhechores, en la misma forma que lo ejecutan en las demás provincias de España los respectivos Capitanes Generales» ${ }^{24}$. Esto permitió a la Diputación crear un pequeño cuerpo policial provincial bajo su mando y diseñar un plan de represión de la criminalidad, basado en la movilización militar de los pueblos, bajo su dirección ${ }^{25}$. Y es que no se rechazaba tanto el contenido de la reforma, como su aplicación por autoridades foráneas. En este caso, las autoridades forales acabaron afirmando con cierto orgullo que en Vizcaya era la propia Diputación quien «hace las veces de Capitán General» ${ }^{26}$.

Como vemos, para la Corona la Diputación General se estaba convirtiendo en un instrumento necesario para aplicar en Vizcaya algunas de sus reformas, bien que adaptadas al ordenamiento foral. De ello derivó un notable fortalecimiento de la institución foral y una expansión de sus atribuciones. Pero al mismo tiempo que la Diputación era instrumento institucional para la aplicación de esas reformas monárquicas, ante la comunidad política vizcaína asumió el papel de garante de la foralidad frente a las tentativas de la Corona de introducir nuevas autoridades o una administración más directa del territorio. Con ello impulsó una lectura del fuero ${ }^{27}$ que subrayaba su contenido como autogobierno provincial en manos de la Diputación, interpretación que alcanzó su pleno desarrollo durante la siguiente centuria, en la época de redefinición y adaptación de la foralidad al sistema político liberal.

\section{LA DIPUTACIÓN, EL CORREGIDOR Y LOS DIPUTADOS GENERALES}

Los componentes esenciales de la Diputación eran el Corregidor, que la presidía, y los dos Diputados Generales, nombrados cada dos años por las

23 LÓPEZ GARRIDO 1987: 25. BALLBÉ, 1983: 25-36.

24 SAGARMINAGA, 1892, vol. 5: 136-137.

25 MARTÍNEZ RUEDA, 2000: 273-288. ENRÍQUEZ, 40 (Bilbao, 2010): 7-27.

26 AFB, AJ 1487/3, 1794, fol. 210-211. La capitanía general era una división administrativa implantada por la nueva dinastía borbónica en la que el Capitán General ejercía, además del máximo poder militar, competencias en la administración y gobierno civil de su distrito.

27 Sobre las diferentes lecturas del fuero en la sociedad vasca del XVIII vid. IÑURRATEGUI, 1997: 179-184. 
Juntas Generales ${ }^{28}$. Además de presidir la Diputación, el Corregidor era en Vizcaya, al igual que en otros territorios peninsulares, depositario de la jurisdicción real, por lo que no sólo administraba justicia, sino que también podía intervenir en el gobierno y administración del territorio ${ }^{29}$. El Corregidor era, pues, una figura institucional con entidad propia que, además, presidía otra institución como la Diputación General, con la que mantuvo frecuentes conflictos durante la segunda mitad del siglo XVIII.

El discurso de las élites vizcaínas presentaba al Corregidor como un elemento extraño al país, desconocedor de su derecho. Esa era la razón por la que, según ese discurso foral, los Corregidores introducían frecuentemente en el Señorío «novedades que no admite su constitución». Contraponían al Corregidor, como autoridad extraña al país, la figura de los Diputados Generales que, «como miembros del cuerpo», protegían los derechos de los vizcaínos:

...siendo [Vizcaya] un país libre y exento, con particulares leyes, fueros, privilegios, usos y costumbres, necesita para la conservación íntegra y sin lesión de su constitución de unos jefes, representantes o diputados que como miembros del cuerpo, celen el interés común y particular ... ${ }^{30}$

Para fortalecer a la Diputación, y dentro de ella a los Diputados Generales, las elites provinciales trataron de asignar al Corregidor un papel secundario en el entramado foral. En ese contexto los conflictos jurisdiccionales entre Corregidor y Diputación fueron frecuentes. Las tensiones institucionales giraron principalmente sobre dos cuestiones: por un lado, el alcance de las capacidades judiciales de los Diputados Generales y, por otro, el ámbito de las atribuciones gubernativas del Corregidor .

El fuero señalaba que los Diputados Generales, junto al Corregidor, eran instancia de apelación de las sentencias dadas por el Corregidor. En el caso de que el Corregidor rechazara la apelación, la parte agraviada podía presentar recurso de inhibición del Corregidor ante los Diputados Generales ${ }^{31}$. El pro-

28 Diputados y Corregidor actuaban auxiliados por otros oficiales también designados por la Junta General: dos síndicos, dos consultores o asesores jurídicos y el secretario que daba fe de los acuerdos. Según ARTIÑANO (1885: 248-252), los síndicos eran los «representantes legales de los derechos de Bizcaya y centinelas de sus libertades, buenos usos y costumbre», por lo que podían vetar los acuerdos antiforales de la Diputación para que fueran sometidos a Junta General.

29 Sobre el significado del concepto iurisdictio en la cultura política de la Edad Moderna vid. HESPANHA, 1993: 61-84.

30 AHN, Consejos leg. 1183, exp. 49, fol. 23 v, 1784.

31 La ley III del título 29 establecía que se podía apelar ante los diputados generales de «qualquier sentencia dada y pronunciada por el Corregidor en causa civil y pecuniaria definitiva o interlocutoria». La ley XI del mismo título señalaba que «en todas las causas que así estuvieren devueltas por apelación o nulidad o por otro remedio alguno ante los diputados de 
cedimiento que debía seguirse en esos recursos, especialmente en lo referente a las inhibiciones, no estaba claramente reglamentado en el fuero, lo que generó frecuentes desacuerdos entre el Corregidor y los Diputados.

Durante la segunda mitad del siglo XVIII, en un proceso desarrollado en pugna con el Corregidor, el Señorío fue definiendo el ejercicio de esas atribuciones, fortaleciendo progresivamente las capacidades judiciales de los Diputados Generales en los recursos de apelación e inhibición. La cuestión principal que se debatía era la capacidad de los Diputados de aceptar por sí solos, al margen del Corregidor, los recursos de inhibición de los autos y sentencias de éste. Finalmente, la Diputación aprobó en 1769 un reglamento sobre el método a seguir en los recursos de apelación e inhibición. La nueva normativa reconocía a los Diputados su posición central en el proceso de apelaciones, ya que «por sí solos, sin dicho señor Corregidor» podían aceptar y resolver los recursos de inhibición, «con acuerdo de su asesor letrado» ${ }^{32}$.

A pesar de la aprobación del nuevo reglamento, los desacuerdos y tensiones entre el Corregidor y los Diputados Generales sobre el alcance de las atribuciones de éstos en los recursos de apelación e inhibición menudearon durante las últimas décadas del siglo XVIII, ya que los Corregidores se resistían a aceptar el protagonismo de los Diputados en la materia. En 1773, por ejemplo, mientras la Diputación acusaba al Corregidor Salcedo de «trastornar toda su quietud» al impedirles conocer las causas en grado de apelación ${ }^{33}$, éste se lamentaba de que los recursos de inhibición presentados ante los Diputados acabasen dilatando las causas. Pocos años después, en 1776, el sucesor de Salcedo en el Corregimiento, Gonzalo Galiano, se quejaba de que los Diputados Generales mediante los recursos de inhibición dilataban las causas y trastornaban «el orden judicial, atando las manos al Corregidor» ${ }^{34}$. Por su parte, el Corregidor Paz Merino denunciaba en 1780 que «el abuso de las inhibiciones que (...) admiten los Diputados» estaba poniendo en riesgo «las facultades y regalías del Corregimiento» ${ }^{35}$. Unos años después, en 1794, era el Corregidor Gabriel Amando Salido quien se quejaba de que los Diputados, utilizando la fórmula del recurso de inhibición, le habían impedido entregar al ejército a varios individuos procesados por vagancia, de lo que deducía que su autoridad había quedado «ajada» y que en el Señorío «el Corregidor no tiene

\footnotetext{
Vizcaya y antes de la definitiva se pidiere por alguna de las partes inhibición o reformación de atentado o de otro agravio que los diputados lo puedan proveer, pero en tal proveer requieran primero al Corregidor...».

32 El reglamento en AFB, AJ 1463/22, 1763; AJ 3171/19, 18 marzo de 1769. Su valoración en PORTILLO, 1991: 316.

33 AHN, Consejos, leg. 12817, exp. s/n, 1773. AFB, AJ 62/50, 1774.

34 PORTILLO, 1991: 317.

35 ARChV, SV, 4605/1, 1780, y 4605/ 2, 1780-1781.
} 
más facultades y autoridad que la que le dispensa y permite tal Diputación $»^{36}$. Y todavía en 1798 el Corregidor criticaba el alcance de las atribuciones judiciales de los Diputados cuando afirmaba no entender que éstos «tengan autoridad y facultades para instruir, seguir y substanciar causas criminales y prender y mandar prender como actualmente está experimentando» ${ }^{37}$.

Como vemos, lo que estaba en discusión era el alcance de las atribuciones judiciales de los Diputados. Mientras algunos Corregidores consideraban la capacidad jurisdiccional de los Diputados «limitadísima y adjunta a la del Corregidor ${ }^{38}$, las élites provinciales le daban una interpretación más amplia y defendían la capacidad de actuar de forma autónoma como tribunal de apelación que, además, podía inhibir al Corregidor. De ello podía derivarse una posición de superioridad de los Diputados sobre el Corregidor, cuyos autos definitivos y sentencias podían anular. Todo parece indicar que fue esta interpretación la que se impuso. Así lo muestran las mencionadas quejas y lamentos de los Corregidores de las últimas décadas del siglo XVIII. Y lo confirman los escritos de algunos fueristas del siglo XIX que presentaban la capacidad judicial de los Diputados, especialmente mediante los recursos de inhibición, como atribución fundamental del poder provincial, ya que permitía modificar las decisiones del Corregidor, incluso en materias tan sensibles como el uso o pase foral. El liberal fuerista Pedro Lemonauría calificaba la figura del recurso de inhibición — «tan odiado de los corregidores, como apreciado y con justa razón por los vizcaínos»- como el «paladión de las libertades del país» ${ }^{39}$. Y el fuerista católico Arístides de Artiñano señalaba que el recurso de inhibición era el instrumento que permitía el síndico «eludir el cumplimiento de lo ordenado por el Corregidor», en el caso de que éste hubiera concedido el uso en contra de su informe. Por eso, lo calificaba como el «derecho más grandioso que ha poseído pueblo alguno», ya que «es el País [representado por los Diputados Generales] quien dicta su propia sentencia» ${ }^{40}$.

Por otro lado, las élites provinciales intentaron anular las capacidades del Corregidor en el ámbito gubernativo, limitándolas a lo contencioso. Según afirmaba un informe del Consultor en 1784, los «magistrados reales» eran oficiales establecidos principalmente «para la administración de la justicia en lo contencioso, civil y criminal, y no para lo gubernativo, político y mili-

36 AFB, AJ 679/3, 1794.

37 PORTILLO, 1991: 323.

38 La expresión es del Corregidor Paz Merino, en ARChV, SV, 4605/1, 1780. Con mayor rotundidad aún se expresaba el Corregidor Colón de Larreategui quien sostenía que los Diputados, por sí solos, nada podían ejecutar «por defecto de jurisdicción, para todo es necesario que recurran al Corregidor...». AHN, Consejos, leg. 1183, exp. 49, fol. 52, 1784.

39 LEMONAURIA, 1837: 10.

40 ARTIÑANO, 1885: 322. 
tar» ${ }^{41}$. Incluso alguna decisión monárquica, como la Real Orden de 1752 que en materia de montes asignaba la jurisdicción gubernativa a las Juntas o a la Diputación y la contenciosa al Corregidor, parecía avalar esa interpretación. Pero es que, además, las elites provinciales trataron de limitar las atribuciones gubernativas del Corregidor en su calidad de miembro y presidente de la Diputación, reduciendo su papel en la institución a la mera presidencia, con carácter puramente honorífico.

El conflicto por esta cuestión estalló en tiempos del Corregimiento de José Joaquín Colón de Larreategui (1782-1786) ${ }^{42}$. Este Corregidor rechazó el papel subordinado que las elites provinciales adjudicaban al Corregidor. Acusó a los Diputados Generales de pretender convertirle «en mero ejecutor forzado de lo que determinan». Trató de fortalecer su papel en el entramado foral y, sobre todo, en la Diputación, ya que, como Corregidor que era, se consideraba «cabeza de la Diputación y de las Juntas, el primero de los del Universal Gobierno de Vizcaya, por Fuero, por Constitución y por Declaraciones Reales». Destacado político del denominado despotismo ilustrado e ideólogo contra la revolución liberal a inicios del XIX, Colón de Larreategui afirmaba que la «fuente de todos los tribunales judiciales y políticos» era el Rey, cuyo único ministro en Vizcaya era el Corregidor, por lo que debía «intervenir y mezclarse en cuantos asuntos se traten por sus Diputaciones y Juntas» ${ }^{43}$.

Esos planteamientos chocaron con algunas prácticas políticas de los Diputados que, presentándose como los representantes de la comunidad vizcaína, tendían a actuar al margen del Corregidor, ya fuera abriendo y respondiendo la correspondencia dirigida al Señorío sin darle noticia, ya presentando memoriales o recursos sin consultarle, ya firmando decretos de la Diputación sin mencionar la figura del Corregidor. Si Colón aspiraba a potenciar su papel en la Diputación, los Diputados Generales lo cuestionaban hasta el punto de negarle el derecho al voto en materias gubernativas. El Consultor San Martín, con el apoyo de los Diputados generales, formuló por escrito los argumentos de las elites provinciales. Diferenciaba dos tipos de Diputación. Por un lado, para administrar justicia estaba el «Tribunal de Corregidor y Diputados», donde se reconocía el derecho a voto al Corregidor. Pero, por otro, estaba la Diputación «como Congreso en el que reside el gobierno, económico y militar», que estaba compuesta por los Diputados, Síndicos y Secretarios, redu-

41 AHN, Consejos leg. 1183, exp. 49, fol. $22,1784$.

42 Una reciente biografía política del personaje, donde se analiza también su actuación y conflictos como Corregidor del Señorío en URQUIJO y ALVAREZ-COCA, 87 (Zaragoza, 2012):171-206.

43 AHN, Consejos, leg. 1183, exp. 49, 1784, fol. 42v-43. Sobre los conflictos entre Colón de Larreategui y los Diputados Generales seguimos las aportaciones de PORTILLO, 1991: 327-332, y de URQUIJO y ALVAREZ-COCA, 87 (Zaragoza, 2012):171-206. 
ciéndose el papel del Corregidor a presidirla, «sin voz, ni voto, que nunca ha tenido, ni puede tener, fuera del decisivo en caso de discordia» ${ }^{44}$. Colón, por el contrario, aseguraba que «el Tribunal de Corregidor y Diputados o la Diputación conoce promiscuamente y bajo un mismo concepto de lo judicial y lo gubernativo» ${ }^{45}$. El pleito se resolvió en el Consejo de Castilla que falló a favor de Colón de Larreategui y decidió que el Corregidor tendría voto en Diputación «en todas las materias gobernativas, económicas y militares» ${ }^{46}$.

Sin embargo, esa sentencia del Consejo de Castilla no supuso ni el fin de las tensiones institucionales entre los Diputados Generales y el Corregidor, ni el fortalecimiento de éste en el entramado foral. Las élites provinciales siguieron tratando de mantener a los Corregidores en un papel irrelevante en la Diputación, subordinado a los Diputados generales. Aunque formalmente se había reconocido el derecho de voto del Corregidor en materias gubernativas, éste nada valía «siempre que los dos señores Diputados vayan conformes en el suyo», como oportunamente le recordaba el Agente en Corte del Señorío, Alejandro Amirola, al Diputado General, Bonifacio de Olaeta ${ }^{47}$.

A fines del siglo XVIII continuaban las tensiones institucionales entre el Corregidor y las autoridades forales. Las elites provinciales seguían afirmando que al Corregidor sólo le correspondía la presidencia de la Diputación y del Regimiento General, sin tener voto en ellos ${ }^{48}$. El Corregidor Gabriel Amando Salido criticaba la conducta política de los miembros de la Diputación con extraordinaria dureza. Acusaba a los Diputados Generales de usurpar «su real jurisdicción». Les recriminaba que ejecutaran la exacción de tributos sin aprobación real. Criticaba que la policía provincial, en lugar de estar a las órdenes del Corregidor, sólo obedeciera a los Diputados. Y, utilizando sus propias palabras, se lamentaba de «la prepotencia de los Diputados y del ajamiento en que me tienen constituido» ${ }^{49}$.

\section{LAS CORPORACIONES LOCALES Y LA DIPUTACIÓN}

Uno de los elementos fundamentales del proceso de fortalecimiento institucional de la Diputación fue su capacidad para establecer una posición preeminente sobre las corporaciones locales que constituían el Señorío. Para

44 El informe del Consultor San Martín (AHN, Consejos, leg. 1183, exp. 48, fol. 20-34), firmado por los Diputados Generales, escandalizó al Corregidor, que pidió y consiguió sentencia ordenando su destrucción en Junta General.

45 AFB, AJ 679/16, 1784, fol. 429.

46 AHN, Consejos, leg. 1183, exp. 49.

47 AFB, AJ 1670/14, 22-11-1784.

48 AFB, AJ 679/5, 1794, fol. 91.

49 AHN, Consejos, leg. 1330, exp. 19, 1797.

Hispania, 2016, vol. LXXVI, nº. 252, enero-abril, págs. 103-128, ISSN: 0018-2141, e-ISSN: 1988-8368, doi: 10.3989/hispania.2016.004 
conseguirlo la Diputación empleó diversos mecanismos y estrategias. En el ámbito de la representación del poder, configuró una imagen de sí misma e impuso un lenguaje y unas formas políticas que denotaban su superioridad sobre los poderes locales. En el ámbito administrativo, fue desarrollando un sistema de gobierno de territorio vizcaíno basado en cierta subordinación jerárquica de los poderes locales al poder provincial. Veámoslo con mayor detalle.

La Diputación se presentaba ante los pueblos como cabeza del cuerpo de provincia y como padre que guiaba a las diferentes comunidades del Señorío, a las que consideraba hijos que debían obedecer y reconocer la dirección de la autoridad paternal. De acuerdo con la cultura política corporativa del Antiguo Régimen, las élites provinciales representaban al Señorío como un «cuerpo místico», que estaba compuesto por diferentes miembros -las corporaciones locales vizcaínas-. La dirección y representación de ese cuerpo correspondía a su «cabeza», que era la propia Diputación. Sin anular la autonomía de los miembros, la cabeza debía mantener la armonía entre ellos y representar la unidad de cuerpo. La imagen de «cabeza», con su función directiva sobre los miembros del cuerpo, iba asociada a la de «padre», como autoridad legítima para administrar el territorio, de la misma forma que lo hacía el pater familias en el ámbito doméstico ${ }^{50}$. Así, los Diputados Generales eran definidos como «la más alta dignidad, ya por ser cabezas de este expresado Señorío como padres de todo el cuerpo místico de que se compone ${ }^{51}$.

El lenguaje empleado por las autoridades locales en su relación con el poder provincial denota la aceptación en muchos casos de ese papel de «protector paternal» de la Diputación, a la que recurrían en momentos de dificultad. Por ejemplo, la villa de Balmaseda, obligada por orden real de 1763 a aprobar su unión con el Señorío, pidió ayuda a la Diputación ya que como «padre universal» debía «extender toda su protección en mi auxilio». De la misma forma, la ciudad de Orduña, compelida a entregar sus cuentas municipales a la Contaduría de Propios y Arbitrios, recurrió al «paternal amor» de la Diputación para ajustar su conducta a su «superior prudencia» ${ }^{52}$.

El protocolo y las formas de tratamiento que la Diputación exigía a los pueblos también nos informa de ese proceso de construcción de la preeminencia. Por ejemplo, la Diputación ordenó en 1769 que los municipios se dirigieran al poder provincial por medio de «memorial»o «representación», y

50 HESPANHA, 1992: 28-31. FRIGO, 1985: 7-14, 193-214.

51 ARChV, S.V., C. 5256, $\mathrm{n}^{\circ}$ 2, fol. 4, 1760. En esta época también fue cobrando protagonismo la imagen del Rey como cabeza de la república y padre de sus súbditos, además de la tradicional como juez supremo. Se trataba con ello de fortalecer las capacidades de gobierno de la Monarquía y el desarrollo de una Monarquía administrativa. Vid. GARRIGA, 13 (México DF, 2004): 13-44.

52 AFB, AJ 1487/2, fol. 122 y 132, 1763. 
nunca mediante «requerimiento», ya que este método parecía suponer una igualdad que era contraria a la superior autoridad de la Diputación ${ }^{53}$. Cuando consideraba que alguna autoridad local desafiaba su supremacía, le mandaba comparecer en Diputación, investigaba lo ocurrido, le exigía explicaciones y decidía si actuaba judicialmente contra ella. Si las autoridades locales aceptaban la superior «paternal» autoridad de la Diputación, reconocían haber actuado equivocadamente y se comprometían a no volver a hacerlo en el futuro, el asunto se solventaba con una simple amonestación. Pero si la Diputación consideraba que la ofensa a su autoridad había sido grave e insolente, entonces trataba de imponer un castigo ejemplar. Es lo que le ocurrió a Juan de Menchaca, vecino de Urduliz, que se atrevió a decir en concejo abierto que los Diputados «sin parte contraria» ordenarían «lo que se les antojaba» ${ }^{54}$. La Diputación decidió encarcelarlo. Algo similar le pasó a José Sangróniz, regidor de Bilbao, de 74 años, que afirmó públicamente que los Diputados estaban vulnerando la autonomía jurisdiccional de la villa. Los Diputados Generales le acusaron de injuriar «a la más alta dignidad» del Señorío, consiguieron que el Corregidor lo encarcelara e insistieron en que permaneciera en prisión, a pesar de su avanzada edad y penoso estado de salud ${ }^{55}$.

En el ámbito jurídico, el monopolio del uso o pase por el poder provincial y su prohibición a las autoridades jurisdiccionales locales fue un mecanismo de gran importancia para afianzar su preeminencia. El uso era un instrumento adecuado al contexto de pluralismo jurídico y jurisdiccional del Antiguo Régimen, cuya función era proteger los derechos y privilegios de las diversas corporaciones. Las autoridades provinciales reclamaban su ejercicio para salvaguardar la foralidad frente a órdenes provenientes del exterior que pudieran vulnerarla. Insistían en que no se pusiera en práctica ninguna orden foránea sin haber pasado previamente por ese filtro ${ }^{56}$. Pero en el entramado foral había autoridades jurisdiccionales locales que pretendían utilizar el uso para garantizar el patrimonio jurídico de sus comunidades y, sobre todo, su autonomía jurisdiccional en primera instancia ${ }^{57}$. Sin embargo, la Diputación se opuso radicalmente a que lo empleasen, ya que ello podía anular su primacía sobre los poderes locales.

Ya en 1735 la Junta General aprobó un decreto que ordenaba que las justicias locales no se «entrometiesen» en la concesión del uso, a raíz de que los

53 SAGARMINAGA, 1892, vol. 4: 463.

54 AFB, AJ 1654/26, 1765.

55 ARChV, SV, C. 5256, n², 1760.

56 Desde ópticas diferentes analizan el instrumento del pase foral en los territorios vascos PORTILLO, 1991: 483-548 y GÓMEZ RIVERO, 1 (1984, San Sebastián): 55-74.

57 MARTÍNEZ RUEDA, 1994:136-138. 
alcaldes de las Encartaciones y su Teniente intervenían en la cuestión ${ }^{58}$. A pesar de ello, algunas autoridades locales continuaron examinando las órdenes procedentes del exterior para ver si vulneraban las ordenanzas y privilegios locales. Por ejemplo, el concejo de Portugalete aprobó en 1756 un decreto que establecía que los despachos que llegaran a la villa debían pasar antes de su ejecución por la censura de su síndico, con el fin de preservar la primera instancia del alcalde. Cuando detuvieron un despacho del Corregidor, la Diputación ordenó la comparecencia del alcalde y del síndico de la villa y les acusó de socavar la autoridad del Gobierno del Señorío. Ante el cariz que estaba tomando el asunto, las autoridades locales alegaron ignorancia, renunciaron al ejercicio del uso y se conformaron con que desde entonces el alcalde comunicara a la Diputación los despachos contrarios a su autonomía jurisdiccional para que fuera esta institución la que «conserve la primera instancia de sus villas». La Diputación se dio por satisfecha, «vista la resignada obediencia con la que la referida villa y sus oficiales se someten a esta Diputación General ${ }^{59}$. Algo parecido ocurrió cuando el alcalde de Elorrio se atrevió a suspender un auto de la Diputación contra un vecino de la villa que no había probado su hidalguía con el argumento de que le constaba que era «vizcaíno legítimo». Se acusó al alcalde de faltar «a la veneración y respeto al tribunal de los Señores de la Diputación general». Como señalaba el síndico del Señorío, este tipo de actuaciones suponía un desafío a la preeminencia y autoridad de los miembros de la Diputación. Sostenía que ninguna autoridad local podía «disputarles ni oponerse a sus determinaciones, permitiéndoseles únicamente por un efecto de benignidad el representar con la veneración debida lo que se les ofreciere». La Diputación mandó comparecer al alcalde y le previno de que no volviera a dar «autos de uso, ni menos embarace, suspenda ni impida el uso y cumplimiento de los Despachos» del Gobierno del Señorío. No le quedó otro remedio al alcalde que reconocer la superioridad de la Diputación y excusarse alegando «ignorancia» ${ }^{60}$. Para evitar casos similares en 1775 la Diputación adoptó un acuerdo que prohibía terminantemente a las autoridades locales examinar las órdenes del poder provincial para concederles o negarles el uso:

Se acordó encargar a los Alcaldes y Tenientes del Señorío que en lo sucesivo se abstengan de dar el uso, con pretexto de su primera instancia, tanto en los despachos que se libran por la Diputación, como en los que se libran por el Corregidor... ${ }^{61}$.

58 AFB, AJ 34/12, 1714-1771.

59 AFB, AJ 1464/6, 1758. SAGARMINAGA, 1898, vol. IV: 292-293.

60 AFB, AJ 680/1, 1775.

61 AFB, Tenencia de la Merindad de Durango, Reg. 2, fol. 274. El decretó contó con algunas resistencias. Las anteiglesias de la Merindad de Durango entendían que era «opuesto a la inmemorial posesión quieta y pacífica de dar uso a todos y cualesquiera despachos de tribu- 
Como resultado de la posición de predominio alcanzada por la Diputación sobre las corporaciones locales, se fue estableciendo de forma paulatina un modelo de administración del territorio basado en el binomio Diputaciónmunicipio. Como la Diputación carecía de un aparato administrativo desplegado por toda Vizcaya, ejerció su papel directivo en el gobierno y administración del territorio a través de los municipios, mediante órdenes a las autoridades locales que éstas debían ejecutar. De esta forma, la Diputación fue interviniendo de manera creciente, pero indirecta, en materias que tradicionalmente habían quedado al arbitrio de los municipios. Como en su día observó Pablo de Alzola, para las últimas décadas del siglo XVIII la Diputación había conseguido establecer una suerte de «tutela» sobre los municipios en los principales ramos de la administración local ${ }^{62}$. Ordenaba a alcaldes de las villas y a los fieles regidores de las anteiglesias que cumplieran sus providencias y amenazaba con castigar su inobediencia. En materia de hacienda mandaba a los pueblos pagar sus contribuciones foguerales y arbitrios provinciales - cuyo rendimiento debían certificar-, conminando a los omisos con multas y venta de bienes municipales ${ }^{63}$. Obligaba a los pueblos a enviar periódicamente a la Secretaría del Señorío testimonio del estado de sus caminos y a repararlos, multando a los que no ejecutaban sus decretos ${ }^{64}$. Exigía a las autoridades locales afinar y enviar a la Secretaría del Señorío las medidas utilizadas en cada pueblo para su cotejo y asegurar así la uniformidad de pesos y medidas en todo el Señorío ${ }^{65}$. Conminaba a los pueblos a enviar testimonio de las personas residentes en cada pueblo y especialmente de los forasteros que no habían hecho constar su nobleza y limpieza de sangre. ${ }^{66}$ En materia de orden público exigía que las autoridades locales organizaran la movilización militar de sus pueblos para reprimir la criminalidad, bajo la dirección y supervisión de la propia Diputación ${ }^{67}$. También desarrolló una política de control moral, que trataba de disciplinar costumbres y comportamientos, mediante órdenes a alcaldes y fieles para regular el horario de las tabernas, el comportamiento en fiestas y romerías, etc., cumpliendo celosamente las órdenes monárquicas en la materia. Incluso rectificaba a las autori-

nales superiores por los Señores Tenientes». Por su parte, la villa de Durango sostenía que el ejercicio del uso era inherente a la autonomía jurisdiccional de los alcaldes de las villas y afirmaba que la Diputación no tenía facultades para suprimir costumbres ni privilegios de las villas. PORTILLO, 1991: 396. MARTÍNEZ RUEDA, 1994: 138-139.

62 ALZOLA, 1910: 17.

63 AFB, AJ01597/017, 1757-1770; AJ03171/022, 1770; AJ01654/017, 1774. SAGARMINGA, 1892, vol. 5: 509, 524.

64 AFB, AJ 01654/019, 1774; AT00021/017, 026, 27, 1774.

65 AFB, AJ 03180/026, 1781; AJ03180/028, 1782. SAGARMINGA, 1892, vol. 5: 66.

66 AFB, AJ01653/071, 1759-70; AJ03171/030, 1772; AJ00612/073, 1775.

67 GRACIA, 1993: 127-171. 
dades locales, prohibiendo bailes o diversiones por éstos autorizados ${ }^{68}$. Sin embargo, la repetición una y otra vez de ese tipo de decretos de la Diputación, la insistencia en conminaciones y multas a las autoridades locales parece indicar su parcial incumplimiento. La propia Diputación se quejaba en 1772 de la «negligencia harto común» de las autoridades locales en el cumplimento de sus órdenes ${ }^{69}$. Es lo que correspondía a un momento de transición como era la segunda mitad del siglo XVIII, a medio camino entre el predominio de la autonomía local hasta entonces imperante y el modelo de administración provincial centralizado que se construirá en el siglo XIX.

Aunque, como hemos visto, el proceso de afirmación de la supremacía de la Diputación sobre los poderes locales se fue consolidando paulatinamente, también tuvo que hacer frente a importantes resistencias. Las más destacadas fueron las que protagonizaron los concejos de las Encartaciones y la villa de Bilbao. En el caso de las Encartaciones, su tenaz oposición a aceptar el papel directivo de la Diputación durante el siglo XVIII fue finalmente superada entre 1799 y 1806 , cuando los diez concejos y valles encartados aprobaron su plena incorporación al Señorío y aceptaron la superior autoridad de la Diputación para obligar a las instituciones locales al cumplimiento de las providencias del Señorío ${ }^{70}$. En el caso de Bilbao, por el contrario, la resistencia de la villa a aceptar la preeminencia del poder provincial generó una conflictividad creciente y enconó las relaciones entre Bilbao y la Diputación durante los últimos años del siglo XVIII. El asunto derivó en una profunda crisis institucional $^{71} \mathrm{y}$ en una grave conmoción social, la llamada zamacolada.

\section{LA EXPANSIÓN DEL ÁMBITO DE PODER DE LA DIPUTACIÓN}

En el orden político del Antiguo Régimen los límites entre los diferentes poderes y jurisdicciones se definían en su propia concurrencia jurisdiccional, a través del ejercicio cotidiano del poder, de la fricción y del conflicto. El sistema era dinámico en el sentido de que los límites del poder de cada una de las instancias se hallaban en constante proceso de definición ${ }^{72}$. En ese contexto la Diputación durante la segunda mitad del siglo XVIII fue definiendo y ensanchando su ámbito de poder, en pugna con otros agentes institucionales, como la

68 AFB, AJ 1654/4, 1772; AJ1654/026, 1766. SAGARMINGA, 1892, vol. 5: 182, 189.

69 SAGARMINGA, 1892, vol. 4: 509.

70 MARTÍNEZ RUEDA, 5 (San Sebastián, 2008): 247-254. PORTILLO, 1991: 283-292.

71 MARTÍNEZ RUEDA, 20 (BILBAO, 2009): 9-26.

72 PORTILLO, 1991: 38-40 y 308-312. LOPEZ ATXURRA, 2004: 83-105. 
Monarquía, el Corregidor o los poderes locales. La consecuencia de ello fue un notable incremento de sus prerrogativas y de su actividad material ${ }^{73}$.

En el ámbito de la administración de justicia el fuero reconocía unas limitadas atribuciones a los Diputados Generales. Por un lado, la denominada jurisdicción de hidalguías correspondía privativamente al Corregidor y los Diputados Generales. Según establecía la Ley XIII del título primero del fuero, los forasteros que querían avecindarse en Vizcaya debían probar su hidalguía ante el Corregidor, «juntamente con los dos Diputados», dando información sobre su linaje y genealogía. En 1758 la Diputación estableció con precisión el procedimiento que debía seguirse en los procesos de probanza de hidalguía y durante la segunda mitad del siglo XVIII la Diputación defendió con firmeza esa facultad privativa ${ }^{74}$. Cualquier autoridad que interviniese en asuntos relacionados directamente o de forma tangencial con la jurisdicción de hidalguías, era inmediatamente reconvenida por la Diputación y amonestada por trasgredir su jurisdicción privativa en la materia ${ }^{75}$. Con similar celo, las autoridades provinciales recordaban periódicamente a alcaldes y fieles de los pueblos su obligación de remitir a la Diputación información sobre los forasteros residentes sin estar avecindados y sin haber acreditado su genealogía.

Por otro lado, además de la jurisdicción de hidalguías, el Fuero reconocía a los Diputados atribuciones judiciales como instancia de apelación de las sentencias del Corregidor. Como hemos señalado en un apartado anterior, durante la segunda mitad del siglo XVIII, en un proceso desarrollado en pugna con los Corregidores, el Señorío fue definiendo el ejercicio de esas atribuciones, fortaleciendo progresivamente las capacidades judiciales de los Diputados Generales en los recursos de apelación e inhibición.

Esas limitadas facultades jurisdiccionales de los Diputados Generales fueron notablemente reforzadas en 1762. Utilizando las influencias de Agustín de Montiano, Secretario de la Cámara de Castilla y protector del Señorío en la Corte, la Diputación consiguió una real orden que facultaba a los Diputados a asumir el Corregimiento, «entendiendo y conociendo como jueces en primera instancia con acuerdo de asesor en todos los negocios y pleitos civiles y criminales», cuando ni el Corregidor ni su Teniente pudiesen hacerlo. Aunque los Corregidores eran reacios a ser sustituidos por un Diputado General y el

73 Similar tendencia se produjo en Guipúzcoa, como ha analizado RUIZ HOSPITAL, 1997: 235-243.

74 Real Confirmación del Reglamento hecho en Junta General de diez y siete de Julio de mil setecientos y cinquenta y ocho, sobre el modo y forma de hacer filiaciones e Hidalguías, s.n., 1759. Una de las razones que motivaron la elaboración y aprobación de ese reglamento fue que, según denunciaban las autoridades provinciales, las Encartaciones estaban «usurpando la jurisdicción privativa que les corresponde por Fuero a los Señores Corregidor y Diputados Generales».

75 AFB, AJ 680/2, 1788-1790; AJ 1263/27, 1796; AJ, 680/1, 1775. 
asunto generó algunas tensiones, la Diputación defendió con firmeza las nuevas atribuciones de los Diputados como Corregidor en ausencias obtenida por orden de 18 de octubre de $1762^{76}$.

El protagonismo alcanzado por los Diputados generales en diversos aspectos de la administración de justicia - jurisdicción de hidalguías, recursos de apelación e inhibición, jurisdicción ordinaria en ausencia del Corregidor-, permitió a la Diputación presentarse en las últimas décadas del siglo XVIII como una especie de «tribunal superior», dotado de cierta preeminencia sobre las justicias ordinarias de los pueblos vizcaínos. Por ejemplo, cuando en 1796 el alcalde de la villa de Otxandio acusó a la Diputación de vulnerar su primera instancia en un asunto concreto, la Diputación le respondió que simplemente había solicitado información sobre la materia, como «qualquiera tribunal superior puede hacer para su instrucción $\rangle^{77}$. Esa condición de tribunal superior le fue formalmente reconocida en el Reglamento para la persecución $y$ castigo de malhechores, aprobado por las Juntas Generales y sancionado por la Corona en 1799. El reglamento, elaborado por el Consultor perpetuo Francisco de Aranguren y Sobrado, incrementó las atribuciones judiciales de la Diputación en los procesos criminales por robo, hurto y muerte, en detrimento de las diversas jurisdicciones ordinarias. Antes de publicar las sentencias, las autoridades jurisdiccionales locales debían remitirlas al Corregidor y Diputados «que son los que componen el Tribunal superior en Vizcaya», para que éstos emitieran la sentencia definitiva. Incluso en las causas penales graves iniciadas por el Corregidor, la sentencia definitiva debía pronunciarse por el tribunal de la Diputación, compuesta por el mismo Corregidor y los dos Diputados Generales, asesorados por dos letrados de su confianza ${ }^{78}$. En suma, la Diputación ya no intervenía sólo como instancia de apelación en los procesos criminales graves, sino que lo hacía directamente, convertida en tribunal superior de Vizcaya.

De la misma forma que en el ámbito de lo contencioso la Diputación fue adquiriendo un protagonismo creciente, también en el campo gubernativo incrementó notablemente sus atribuciones. Para ello las elites provinciales formularon un discurso en el que defendían la preeminencia de la «jurisdicción gubernativa» de la Diputación, del Regimiento General o de las Juntas Generales, sobre otros poderes y jurisdicciones del entramado foral en aquellas materias que afectaban al conjunto del territorio vizcaíno. Según las autoridades forales, pertenecía «privativamente al Señorío en Junta, Regimiento o

76 AFB, AJ 3/28, 1768; AJ 317/12, 1762. AREITIO, 1943:110-115. AHN, Consejos, leg.10101, exp. s/n, 1762; leg. 1330, exp. 19, 1789-1797.

77 AFB, 1263/28, 1796.

78 PORTILLO, 1991: 331-332. SAGARMINAGA, 1892, vol. V: 542-545. SAGARDUY, 5 (Bilbao, 1988): 139-158. 
Diputación la Jurisdicción gubernativa, política y económica para los casos que en lo universal miran a la conservación de los pueblos en común, buen régimen, economía y comercio de sus frutos y mantenimientos...» ${ }^{79}$. Aunque el discurso foral atribuía el ejercicio de esa jurisdicción gubernativa al Señorío, encarnado tanto en las Juntas y el Regimiento como en la Diputación, de hecho fue esta última institución la que se encargó de su gestión cotidiana.

No es posible delimitar con precisión el alcance de esa jurisdicción gubernativa porque las élites provinciales la definían de una manera ambigua, abierta y flexible. Incluían en ella de forma genérica todas las materias que afectaran a los pueblos vizcaínos sobre las que las Juntas, el Regimiento o la Diputación pudieran tomar decisiones:

Bien entendido que son y han de entenderse por de esta naturaleza [gubernativa], según la costumbre establecida, los acuerdos y decretos que se hicieren para lo universal del distrito del Señorío, así en punto de pesos y medidas, de vena y carbón, uniformidad de las tocantes a mantenimientos, reparos de caminos, plantío y conservación de montes, precio y extracción de castaña, su buena administración y repartimientos y de la vena de Yerro, como en todas las demás cosas y casos que el Señorío ha acostumbrado providenciar y mandar en Junta, Regimiento o Diputación, sin que se pueda introducir ni oponer limitación alguna ${ }^{80}$.

Esta definición flexible de la «jurisdicción gubernativa» le daba un carácter dinámico que permitió a la Diputación ensanchar paulatinamente su contenido. Paradójicamente también contribuyó a ello el desarrollo durante el siglo XVIII de una monarquía administrativa que trató de gobernar el reino de forma más directa y ejecutiva. Como hemos visto en un apartado anterior, esas medidas monárquicas se aplicaron en el Señorío de manera singular y limitada. La resistencia del poder provincial a aceptar nuevas autoridades ajenas al sistema foral se solventó en algunos casos concediendo a la Diputación la gestión de esas materias, que el poder provincial incluyó en su jurisdicción gubernativa.

Al amparo de esa imprecisa jurisdicción gubernativa la Diputación desarrolló durante la segunda mitad del siglo XVIII un creciente protagonismo en el gobierno y administración del territorio, asumiendo la gestión de nuevas competencias, de forma que a finales de la centuria se definía a sí misma como la institución que «tiene sobre sí el Gobierno de todos los pueblos de su distrito en todo lo que es general de él» ${ }^{81}$. Por eso intervenía en multitud de

79 AFB, Encartaciones, Reg. 1, leg. 6, no 4; Pleitos y Autos, Reg. 21, no 145.

80 AFB, Encartaciones, Reg. 1, leg. 6, n ${ }^{\circ} 4$.

81 AMB, ANTIGUA, 324/1/1, 1790. La Diputación sólo aceptaba como excepción a su capacidad de intervención «los casos y cosas que preservaron en sus ordenanzas y las correspondientes por derechos peculiares y privativos...». 
materias que iban desde la uniformidad de pesos y medidas hasta el control moral de fiestas y romerías ${ }^{82}$. Regulaba el abastecimiento de los pueblos en momentos de escasez y carestía ${ }^{83}$. Daba numerosas providencias para hacer cumplir en Vizcaya órdenes monárquicas de carácter general. Controlaba a los pueblos en numerosos asuntos que iban desde sus contribuciones fiscales hasta el estado de sus caminos ${ }^{84}$. Se encargaba de ejecutar los decretos aprobados por las Juntas Generales. Ejercía «la jurisdicción gubernativa económica» en materia de montes y política forestal ${ }^{85}$. Dictaba numerosas medidas de control social para la represión de mendigos y vagabundos ${ }^{86}$. Creó una pequeña fuerza policial provincial que actuaba bajo su mando. Dirigía la represión de la criminalidad, mediante ese cuerpo policial y mediante movilización militar ordenada en los pueblos, que supervisaba ${ }^{87}$. En los últimos años del siglo XVIII y XIX consiguió gestionar una amplia administración fiscal basada en contribuciones directas e impuestos sobre el consumo de radio provincial ${ }^{88}$. En suma, la «jurisdicción gubernativa» de la Diputación era extraordinariamente amplia y le permitía intervenir de forma genérica en la administración del territorio ${ }^{89}$. Como hemos visto en el anterior apartado, lo hacía a través de las autoridades locales, sobre las que había conseguido establecer una relación de preeminencia.

\section{CONCLuSIONES}

Durante la segunda mitad del siglo XVIII la Diputación General del Señorío de Vizcaya conoció un proceso de notable fortalecimiento institucional. Paradójicamente, uno de los agentes que contribuyó a ello fue la Monarquía del denominado Absolutismo Ilustrado. Aunque en la dialéctica entre reforma ilustrada y privilegio foral se manifestaron tensiones, la Corona y el Señorío tendieron a buscar soluciones de compromiso que conciliasen la foralidad con las medidas monárquicas. Uno de los elementos básicos del discurso foral era el rechazo a aceptar autoridades ajenas al sistema foral. Por eso la Monarquía confió la aplicación de algunas de sus reformas a la propia Diputación, lo que

82 AFB, AJ 1654/4, 1772; AJ 1654/26, 1765; AJ 613/52.

83 AFB, AJ 1262/87, 1789.

84 AFB, AJ 1597/17, 1757-1770.

85 AFB, AJ 679/18, 1779; AJ 1259/8, fol. 55-57, 1802.

86 GRACIA, 1993: 127-171.

87 MARTÍNEZ RUEDA, 2000: 273-288.

ENRÍQUEZ, 40 (Bilbao, 2010): 7-27.

88 LÓPEZ ATXURRA, 1999: 556-565.

89 Así lo prueba la recopilación de decretos de la Diputación que puede verse en LARREA y MIEZA, 1992: 412-539. 
contribuyó a su robustecimiento. Paralelamente, la Diputación asumió ante la comunidad política vizcaína el papel de custodio del fuero al mostrar una tenaz resistencia a aceptar medidas que consideraba contrarias a la foralidad. De esta forma, a la par que se fue convirtiendo en institución necesaria para aplicar en Vizcaya las órdenes reales, la Diputación fue impulsando en la práctica una lectura de la foralidad que subrayaba su contenido como poder provincial, más que como costumbres, usos y exenciones diversas de origen medieval.

Al mismo tiempo, la Diputación consiguió establecer una posición preeminente sobre otras instituciones y corporaciones del plural y complejo entramado foral. En una dinámica institucional conflictiva, las elites provinciales trataron de relegar al Corregidor a un lugar secundario en la estructura foral y subordinado en muchos casos a los Diputados Generales. Contraponían al Corregidor, presentado como autoridad foránea e ignorante de la «constitución» del país, la figura de los Diputados Generales que, «como miembros del cuerpo», protegían los derechos de los vizcaínos ${ }^{90}$. Aunque el Corregidor era presidente de la Diputación, los Diputados Generales quisieron adjudicarle un papel puramente honorífico en la institución. En lo gubernativo, intentaron eliminar su participación privándole del derecho de voto en las reuniones de la Diputación. Los Diputados Generales también asumieron un papel destacado en la administración de justicia, mediante su participación en los recursos de apelación e inhibición de las sentencias del Corregidor, cuyos autos definitivos y sentencias podían llegar a anular.

Ante las corporaciones locales que constituían el Señorío, la Diputación fue construyendo una relación de superioridad. En el ámbito de la representación del poder, se atribuyó el papel de «cabeza del cuerpo místico» del Señorío y «autoridad paternal» de todos los pueblos ${ }^{91}$, al tiempo que impuso un protocolo y formas de tratamiento que denotaban superioridad y jerarquía sobre las autoridades locales. En lo referente al gobierno del territorio, la Diputación se definió como titular de la «jurisdicción gubernativa» en los asuntos que afectaban a todos los pueblos vizcaínos, lo que le permitió desarrollar un sistema de gobierno basado en su tutela sobre las autoridades locales, que debían ejecutar sus órdenes. A inicios del siglo XIX la Diputación había conseguido imponer su preeminencia sobre el conjunto de las corporaciones locales vizcaínas, con la excepción de la villa de Bilbao.

Como resultado de todo ello, la Diputación consiguió ampliar extraordinariamente su ámbito de poder durante las últimas décadas del siglo XVIII. La Diputación, titulada Capitán General del Señorio, dirigía su movilización militar, controlaba una pequeña fuerza policial, encabezaba la represión de la

90 AHN, Consejos, leg. 1183, exp. 49, fol. 23 v., 1784.

91 ARChV, SV, C 5256, no 2, fol. 4, 1760. 
criminalidad, gestionaba una creciente administración fiscal provincial y trataba de gobernar en el territorio mediante su preeminencia sobre las autoridades locales. A inicios del siglo XIX la Diputación se definía a sí misma como Tribunal Superior de Vizcaya y como titular de la «jurisdicción gubernativa» en los asuntos comunes a toda Vizcaya.

\section{BIBLIOGRAFÍA}

Agirreazkuenaga, Joseba, Vizcaya en el siglo XIX. Las finanzas públicas de un Estado emergente, Bilbao, UPV-EHU, 1987.

Agirreazkuenaga, Joseba (ed.), La articulación político-institucional de Vasconia: Actas de las Conferencias firmadas por los representantes de Alava, Bizkaia, Gipuzkoa y eventualmente de Navarra (1775-1936), Bilbao, Diputación de Bizkaia, 1995.

Agirreazkuenaga, Joseba: The making of the Basque Question. Experiencing SelfGovernment, 1793-1877, Reno, Center of Basque Studies-University of Nevada, 2011.

Angulo Morales, Alberto, Las puertas de la vida y la muerte: la administración aduanera en las provincias vascas (1690-1780), Bilbao, UPV-EHU, 1995.

Alzola, Pablo, Régimen administrativo antiguo y moderno de Vizcaya y Guipúzcoa, Bilbao, Imprenta de la Casa de Misericordia, 1910.

Areitio, Darío, El Gobierno Universal del Señorio de Vizcaya, Bilbao, Junta de Cultura de Vizcaya, 1943.

Arrieta Alberdi, Jon, «Los fundamentos jurídico-políticos del Escudo de Pedro de Fontecha y Salazar (m. 1753)», Notitia Vasconiae, 1 (San Sebastián, 2002), 131-148.

Arrieta Alberdi, Leyre, «Por los derechos del pueblo vasco. El PNV en la Transción (1975-1980)», Historia del Presente 19 (2012), 39-52.

Artiñano, Arístides, El Señorío de Vizcaya histórico y foral, Barcelona, La Peninsular, 1885.

Astigarraga, Jesús, «Aduanas forales, integración económica y reformismo ilustrado», Notitia Vasconiae, 2 (San Sebastián, 2003), 203-238.

Castells, Luis, «La abolición de los fueros vascos», Ayer, 52 (Madrid, 2003): 117150.

Clavero, Bartolomé, «A manera de Vizcaya: las instituciones vascongadas entre fuero y constitución», A.H.D.E, 58 (Madrid,1988): 543-560.

Clavero, Bartolomé,. Fueros Vascos. Historia en tiempo de Constitución, Barcelona, Ariel, 1985.

Enríquez, Javier, «Los orígenes de la policía en Vizcaya. La Partida Volante (17811824)», Historia Contemporánea 40 (Bilbao: 2010), 7-27.

Fernández Albaladejo, Pablo, «La Monarquía», en Actas del Congreso Internacional sobre Carlos III y la Ilustración. Tomo I, El Rey y la Monarquía, Madrid, Ministerio de Cultura, 1989; 1-89. 
Fernández Pardo, Francisco, La independencia vasca. La disputa sobre los fueros, Madrid, Nerea, 1990.

Fontecha y Salazar, Pedro, Escudo de la más constante fe y lealtad, s/1, s/a.

Frigo, Daniela, Il padre di familia: governo della casa e governo civile nella tradizione dell'economica tra cinque e seicento, Roma, Bulzonia, 1985.

Garriga, Carlos, «Orden jurídico y poder político en el Antiguo Régimen», Istor. Revista de historia internacional, 16, 2004: 13-44. Disponible en: www.istor.cide. edu/archivos/num_16/dossier1.pdf [Consultado el 27 de diciembre de 2013].

Gracia, Juan, Mendigos y vagabundos en Vizcaya /1766-1833), Leioa, UPV-EHU, 1993.

Gómez Rivero, Ricardo, El pase foral en Guipúzcoa en el siglo XVIII, Diputación de Gipuzkoa, San Sebastián, 1982.

Hespanha, Antonio Manuel, Poder e instituçoes no Antigo Regime, Lisboa, Cosmos, 1992.

Iñurrategui, José María, Monstruo indómito: rusticidad y fiereza de costumbres. Foralidad y conflicto social al final del Antiguo Régimen en Guipúzcoa, Bilbao, UPV-EHU, 1997.

Larrea, María Ángeles y Mieza, Rafael (dirs.), Legislación de los actos legislativos dispuestos por las Juntas del Señorío, sus Regimientos y Diputaciones Generales, Bilbao, Diputación de Bizkaia, 1992.

Lemonauria, Pedro, «Ensayo crítico sobre las leyes constitucionales de Vizcaya», Bilbao, Imprenta N. Delmas, 1837.

López Atxurra, Rafael, La administración fiscal del Señorío de Vizcaya (1630-1804), Bilbao, Diputación de Bizkaia, 1999.

López Atxurra, Rafael, «Las instituciones del sistema foral en Euskal Herria», en Agirreazkuenaga, Joseba (dir.), Historia de Euskal Herria. Historia General de los Vascos, Bilbao, Lur, 2004, vol. III; pp. 83-105.

Martínez Rueda, Fernando, Los poderes locales en Vizcaya: del Antiguo Régimen a la Revolución Liberal (1700-1853), Bilbao, UPV-EHU, 1994.

Martínez Rueda, Fernando, «La formación histórica de la policía foral en Vizcaya (1770-1833) », en Gracia, Juan y Mieza, Rafael (eds.), Haciendo Historia. Homenaje a $M^{a}$ Angeles Larrea, Bilbao, 2000; 273-288.

Martínez Rueda, Fernando, «Las Juntas de Avellaneda en el Antiguo Régimen», Iura Vasconiae 5 (2008), 221-256.

Martínez Rueda, Fernando, «El Concejo de Bilbao en vísperas de la invasión napoleónica: una institución en crisis», Bidebarrieta 20 (Bilbao, 2009), 9-26.

Martínez Rueda, Fernando, «La Monarquía borbónica y el Señorío de Vizcaya en la segunda mitad del siglo XVIII: ¿centro contra periferia?», Historia Constitucional [en red], 14 (2013): 129-147. Disponible en: http://www.historiaconstitucional.com [consultado el 20 de diciembre de 2013].

Mañaricua, Andrés: Historiografía de Vizcaya, Bilbao, La Gran Enciclopedia Vasca, 1973.

Monreal, Gregorio, Las instituciones públicas del Señorio de Vizcaya (hasta el siglo XVIII), Bilbao, Diputación de Bizkaia, 1974. 
Pérez Núñez, Javier, La Diputación Foral de Vizcaya. El régimen foral en la construcción del Estado liberal, Madrid, Centro de Estudios Constitucionales, 1996.

Portillo, José María, Los poderes locales en la formación del régimen foral. Guipúzcoa, 1812-1850, Bilbao, UPV-EHU, 1987.

Portillo, José María, Monarquía y gobierno provincial. Poder y constitución en las provincias vascas (1760-1808), Madrid, Centro de Estudios Constitucionales, 1991.

Portillo, José María y Viejo, Julián, «Estudio introductorio», en Aranguren y Sobrado, Francisco, Demostración de las autoridades de que se vale el doctor D. Juan Antonio Llorente, Leioa, UPV-EHU, 1994; 11-76.

Portillo, José María El sueño criollo. La formación del doble constitucionalismo en el País Vasco y Navarra, Donostia, Nerea, 2006.

Ruiz Hospital, Gonzalo, El gobierno de Gipuzkoa al servicio de su Rey y bien de sus naturales. La Diputación Provincial: de los Fueros al Liberalismo, San Sebastián, Diputación de Guipúzcoa, 1997.

Rubio Pobes, Coro, Revolución y tradición. El País Vasco ante la Revolución liberal y la construcción del Estado español, 1808-1868, Madrid, Siglo XXI, 1996.

Sagarduy, José Luis, «La política criminal y penal en Vizcaya a finales del Antiguo Régimen», en Ernaroa, 5 (1988), 139-158.

Sagarmínaga, Fidel, El Gobierno y el régimen foral del Señorío de Vizcaya desde el reinado de Felipe Segundo hasta la mayor edad de Isabel Segunda, Bilbao, 1892, 8 vol.

Urquijo, José Ramón y Álvarez-Coca, Ma Jesús, «José Joaquín Colón y la rehabilitación política de la Monarquía Absoluta», Jerónimo Zurita, 87 (2012), 171-206.

Recibido: 07/01/2014

Aceptado: 25/06/2014 